CIUDAD Y TERRITORIO

ESTUDIOS TERRITORIALES

ISSN(P): 1133-4762; ISSN(E): 2659-3254

Vol. LIII, № 207 , primavera 2021

Págs. 141-152

https://doi.org/10.37230/CyTET.2021.207.08

\title{
Ciudad informal, territorialidades de producción social del espacio urbano en asentamientos humanos
}

\author{
Yonier CASTAÑEDA-PÉREZ ${ }^{2}$ \\ Ana Catalina Hernández-Ramírez ${ }^{3}$
}

Docentes investigadores. Universidad La Gran Colombia (Armenia-Colombia).

RESUMEN: ${ }^{1}$ Se desarrolla la categoría de ciudad informal como acción de territorialización que se materializa por medio de producción social del espacio, en tanto proceso y producto de la segregación socioespacial urbana en la búsqueda del derecho al territorio. A su vez, se evidencia, a partir del caso de la ciudad de Armenia - Quindío (Colombia), cómo la configuración territorial de esta se debe, en gran medida, a la producción de ciudad informal, situación que debe ser tenida en cuenta por las diferentes políticas de ordenamiento territorial. Finalmente, se indaga en cómo las condiciones de un fragmento de ciudad informal en Armenia no solo han sido una respuesta de adecuación y superación de condiciones a las que han sido relegados sus pobladores, de igual forma, se revela que tal situación forma un escenario de su realidad que configura luchas por la territorialización de sus derechos.

PALABRAS CLAVE: Ciudad informal; Producción social del espacio; Segregación socio-espacial urbana; Derecho al territorio.

Recibido: 09.03.2020; Revisado: 18.06.2020;

Correo electrónico: castanedapyonier@miugca.edu.co; No ORCID: https://orcid.org/0000-0003-0484-0253.

Correo electrónico. hernandezramana@miugca.edu.co; No ORCID: https://orcid.org/0000-0003-0221-7636.

Los autores agradecen los comentarios y sugerencias realizados por los evaluadores anónimos, que han contribuido a mejorar y enriquecer el manuscrito original.

${ }^{1}$ Este artículo hace parte de los resultados que se arrojan en uno de los sectores de estudio del proyecto de investigación doctoral "Interpretaciones desde los intersticios. Una lectura de la producción social del espacio urbano informal en Armenia entre los años 1999-2019", que el autor CASTAÑEDAPÉrez adelanta en el Doctorado en Estudios Territoriales de la Universidad de Caldas - Colombia.

${ }^{2}$ Arquitecto Universidad Nacional de Colombia, Magíster en Medio Ambiente y Desarrollo Sostenible Universidad de Manizales, Doctorando en Estudios Territoriales de la Universidad de Caldas, Docente-investigador Facultad de Arquitectura Universidad La Gran Colombia - Armenia (Armenia - Colombia). Líder del grupo de investigación en Territorio y Arquitectura Sustentable.

${ }^{3}$ Arquitecta Universidad La Gran Colombia - Armenia, Quindío. Magister en Hábitat Universidad Nacional de Colombia - sede Bogotá. Docente-investigadora Facultad de Arquitectura Universidad La Gran Colombia (Armenia - Colombia). 


\title{
Informal city, territorialities of social production of urban space in human settlements
}

\begin{abstract}
The category of informal city is developed as an action of territorialization that materializes the notion of the social production of space, as a process and product of urban socio-spatial segregation in the search for the right to territory. Subsequently, it is evidenced from the case of the city of Armenia (Colombia), how the territorial configuration of this and other cities is due, to a great extent, to the production of informal city, a situation that must be taken into account by the different policies of territorial ordering. Finally, it is investigated how the conditions of an informal city fragment in Armenia not only have been a response of adaptation and overcoming conditions to which their inhabitants have been relegated, in turn, it is evident that such situation forms a scenario of their reality that configures struggles for territorialization of their rights.
\end{abstract}

KEYWORDS: Informal city; Social production of space; Urban socio-spatial segregation; Right to territory.

\section{Introducción}

"La espacialidad humana en todas sus formas y expresiones se produce socialmente. Creamos nuestras geografías, para lo bueno y para lo malo, de forma justa e injusta. Por tanto, se puede decir de forma similar que creamos nuestras historias, bajo condiciones que no son de nuestra propia elección, sino en contextos del mundo real que ya han sido formados en el pasado por procesos socioespaciales (...)" (SoJA, 2014:149)

Los espacios urbanos informales, aceleradamente extendidos y presentes en gran parte de las ciudades del "sur global", son comúnmente vistos como una fuente de inestabilidad política y social, como la manifestación espacial de la exclusión social urbana, o como la producción de espacios al margen o en contraposición del orden formal (WACQUANT, 2007; TARDIN, 2006; DUHAU, 2003; ABRAMO, 2012a). Sin embargo, estos territorios empiezan a constituirse como una estrategia recurrente de acceso al espacio urbano, y su proliferación es evidencia de que no se trata de una maniobra excepcional de acción colectiva y resistencia (HARVEY, 2012); por el contrario, sus habitantes han demostrado que, en su formación social, estas territorialidades contienen diversas y creativas estrategias de producción de su propio hábitat (AUBÁN BORRELL, 2017) y, por tanto, son un producto espacial resultante de una necesidad social.

\section{Al respecto Fernández Wagner señala:}

"El acelerado crecimiento de las ciudades latinoamericanas que tendría lugar a partir de los años '50 provocado por importantes desplazamientos poblacionales, que superaban el crecimiento vegetativo de estas ciudades, encontrarán un parque habitacional que no podía albergar más población. Esto, asociado a la débil o inexistente planificación y/o un Estado con pocas posibilidades de construir viviendas nuevas provoca un proceso de asentamiento en tierras vacantes (en forma regular o irregular) en intersticios urbanos (en la mayoría de los casos en áreas no aptas para la urbanización) o la extensión de las periferias, así como el desarrollo de un proceso de construcción de viviendas por parte de los propios pobladores y la posterior lucha por la urbanización y regularización de los barrios. (FERNÁNDEZ WAGNER, 2008: 18)"

Esto significó que millones de nuevos habitantes urbanos pobres auto-produjeran su vivienda, los servicios, el equipamiento comunitario, su hábitat y su espacio; es decir, "construyeran" ciudad.

De ahí, la necesidad del estudio de estos hechos territoriales sin desconocer la vida social que allí ocurre, lo que requiere de un equilibrio analítico de lo que acontece entre su espacio y la sociedad, dado que, todo lo que es social coincide connaturalmente con lo espacial (APRILE-GNISET, 1992). Este enfoque evitaría, por un lado, que estos espacios sean vistos únicamente como un simple escenario $y$, por otro, que la conciencia espacial en la que estamos insertos intensifique múltiples formas de discriminación y multiplique las desigualdades urbanas existentes.

Se parte de la premisa de que la ciudad informal, en tanto hecho territorial y categoría de análisis, es producto de las dinámicas propias de una producción irregular del espacio urbano por parte de grupos humanos marginados o segregados; lo que es, a su vez, una acción colectiva sobre el suelo urbano motivada por la lógica de la necesidad (ABRAMo, 2003; ABRAMo, 2010; ABRAMo, 2012b; CraVINo, 2006) que impulsa a ejercer el derecho al territorio (NATES-Cruz, 2018), a la ciudad (LefEBVRE, 1968; HARVEY, 2012) y a la justicia espacial (SOJA, 2014).

En tal sentido, y con el fin de darle un anclaje espacial al análisis de estos conceptos, se reconocen 
dichas características de la ciudad informal al abordar una ruta representativa en Armenia-Quindío (Colombia); ciudad que, por su condición de capital en un departamento localizado en el centro el país, se ha consolidado en respuesta a procesos migratorios tanto internos como externos al recibir población, particularmente, durante el éxodo rural desarrollado a partir de la segunda mitad del siglo XX en Colombia. Estos eventuales traslados de población en busca de trabajo y oportunidades configuraron en la ciudad un proceso de segregación territorial que se refleja en desigualdades de acceso al suelo urbano.

Resulta pertinente ahora, acotar dos hechos que marcaron un antes y un después en las dinámicas geosociohistóricas de dicha ciudad, ambos ocurridos en el año 1999. Uno de ellos lo constituyó la adopción del primer Plan de Ordenamiento Territorial (POT) para el municipio de Armenia (CONCEJO Municipal de ARMENIA, 1999), a su vez, el primero aprobado en el país producto de la Ley 388 (CoNgReso De La República De Colombia, 1997). El segundo, el fuerte sismo que sacudió la región del eje cafetero colombiano el 25 de enero de aquel año, justo un día después del primer hecho mencionado. Estos sucesos (que desencadenaron nuevas migraciones) a su vez modificaron, en buena medida, el patrón de ocupación del espacio urbano y dieron lugar a una nueva ciudad que subvirtió a la anterior al cambiar los usos del suelo y aumentar aceleradamente el consumo, la ocupación y la apropiación de espacios urbanos. Ambos acontecimientos marcaron un período importante en la reconfiguración del territorio y pusieron de manifiesto diferentes miradas y apuestas institucionales sobre las dinámicas socioespaciales de la ciudad en ese momento histórico.

Con todo y lo anterior, con el fin de constatar que ninguna sociedad, por elemental que sea, escapa a la necesidad de organizar el campo operatorio de su acción (RAFFESTIN, 2011: 106), el presente artículo indaga en cómo las condiciones de un fragmento de ciudad informal en Armenia ha sido una respuesta ingeniosa y muy eficiente de adecuación y superación de condiciones desfavorables a las que fueron relegados algunos grupos poblacionales (Puente Burgos, 2003: 11). Asimismo, se evidencia que tal situación no es independiente del funcionamiento de la sociedad ni del resto de la ciudad, sino que, por el contrario, se forma un escenario de la realidad de manera dialéctica entre el habitante - espacio, quien termina por buscar autonomía, expresar horizontes y sentidos, y que, finalmente, sitúa luchas específicas en la permanente territorialización de sus derechos.

No se trata, por tanto, de una nueva conceptualización de los términos marginal, irregular o informal y segregación, sino de la ejemplificación de estos en un escenario de ciudad informal en perspectiva de ejercicios de territorialización; en una vía de pensamiento que reconoce la necesidad de avanzar en un conocimiento que piense a las ciudades con sus sujetos para hacerlas más democráticas y más justas (Fraser, 2008; Cravino, 2006) al considerar al menos tres elementos: reconocimiento, redistribución y participación.

De modo que, se presenta un ejercicio que involucra complejidades territoriales, algo que demanda la identificación de sujetos y/o actores, y sus intereses (en ocasiones semejantes o disímiles), así como de los entramados institucionales y las relaciones de poder existentes y convergentes en la ciudad informal - en tanto hecho territorial y categoría de estudio- en un contexto cercano. Todo ello con el fin de prever si desde esta otra ciudad es posible crear ordenamientos espacio-temporales alternativos en los que los grupos humanos y los individuos puedan satisfacer sus necesidades y deseos; es decir, diferentes respuestas a quienes viven las implicancias de un modelo que mira de costado a miles de habitantes - especialmente a los grupos desposeídos en el acceso a un hábitat digno-y que les otorgue la oportunidad de ejercer su derecho al territorio.

\section{La ciudad informal: producto y proceso de segregación socioespacial urbana}

"Mientras crece sobre un suelo que es propiedad de pocos, la ciudad no puede ser patrimonio de todos" (Aprile-GnISET, 1992: 796).

En las ciudades, el hábitat informal implica dos formas de transgresión -no necesariamente excluyentes- con relación al proceso de urbanización. La primera se asienta en la falta de títulos de propiedad, es decir, respecto a los aspectos de dominio; la segunda, en el incumplimiento de las normas de urbanización y construcción de ciudad. Cada una de ellas se materializa en diferentes tipos de informalidad en los cuales intervienen múltiples actores que definen distintas formas de segregación urbana.

Por su parte, al hablar de segregación socioespacial urbana, esta implica un distanciamiento y separación localizada de grupos de población en sectores específicos de ciudad, con ello, se conforman áreas socialmente homogéneas. De acuerdo con Clichevsky, este tipo de segregación se presenta en el momento en que los espacios destinados para diversos grupos humanos no son utilizados o configurados de una manera integradora (2000). Lo que, en muchas ocasiones, se traduce en guetos urbanos. 
También es posible entender la existencia de segregación socioespacial cuando esta se produce a partir de dinámicas de (des)(re)territorialización que lleva a grupos humanos, bien sea, a auto producir su hábitat por fuera de los estándares urbanísticos y normativos formales (CASTAÑEDA-PÉREZ 2019), o bien, a establecer áreas socioeconómicas y culturalmente homogéneas al intentar acceder a un efectivo goce y disfrute de la ciudad. Este tipo de situaciones, que ocurren tanto en escenarios de informalidad urbana, como en sectores formales de ciudad, se configuran, según Abramo (2012b), en

\begin{abstract}
"convenciones urbanas [que] son jerarquizadas y sirven de mecanismo cognitivo, un mecanismo que garantiza la estructura segmentada y jerarquizada de las externalidades de vecindad y, por lo tanto, de la estructura socioespacial urbana segmentada (segregada) y desigual. (Pág. 59)"
\end{abstract}

De igual manera, la intervención pública influye en la división del suelo a través de la imposición de normas urbanísticas-, sin embargo, son las relaciones sociales las que finalmente orientan la organización (y ocupación) del espacio urbano (RoNCAYOLO, 1990); aunque estas no precisamente se oponen a los intereses privados ni corrigen las disposiciones asociadas con la segregación.

\subsection{Acerca de la ciudad informal}

Ahora bien, la ciudad informal tiene como particularidad, por un lado, ser producto de la ocupación individual o colectiva de suelos públicos o privados que, en muchos de los casos, no cuentan con las características necesarias para ser urbanizados; $y$, por otro lado, el conformar barrios carentes de servicios básicos por autoconstrucción de viviendas precarias al margen de las normas urbanísticas. Según PINO VÁsqUEZ y OJedA LedESMA (2013) la ciudad informal está conformada por todas aquellas prácticas urbanísticas instauradas, desarrolladas y consolidadas por fuera de la legislación, las normas y las dinámicas de mercado que permiten un acceso formal al suelo urbano y a la vivienda; e involucran, por tanto, la adquisición de terrenos y la autoconstrucción de las viviendas.

Se trata entonces, de una realidad territorial conformada por sujetos individuales o colectivos y actores sociales públicos o privados que configuran las condiciones urbanas para la formación y establecimiento de dichas territorialidades, constitutivas de los espacios urbanos informales. A su vez, se han convertido en reflejo de la segregación socioespacial en las ciudades latinoamericanas en donde, según el programa de las Naciones Unidas para los asentamientos humanos (ONU-HÁBITAT) "una de cada cuatro personas que habitan en áreas urbanas están ubicadas es este tipo de lugares"
(2012: 64) como resultado de los movimientos migratorios campo-ciudad y a la movilidad interurbana que recientemente se concentra en las ciudades intermedias y pequeñas (JANOSCHKA, 2005). Lo que ha producido una narrativa discontinua del territorio que se manifiesta en las grandes e injustas desigualdades urbanas (SABATINI, 2006; VARGAS-DÍAZ \& al., 2010) ante la principal alternativa que han tenido muchos hogares para resolver, aunque de forma inadecuada, sus necesidades habitacionales.

Esta forma de producción (social) del espacio no obedece únicamente al carácter jurídico de la propiedad, la cual convencionalmente estipula que para tener derecho y disponer sobre de ella se debe gozar de un poder legal. Al contrario, esta configuración de nuevos territorios se sustenta en las bases del deber ser del derecho, que parte del supuesto de que todos somos libres e iguales ante la ley pero que, finalmente, termina sin incorporar efectivamente la vida urbana en el derecho. Tampoco obedece al ejercicio formal del mercado de suelo urbano y de las edificaciones que, se supone, es la lógica para el funcionamiento y la reproducción del capital que producen las ciudades modernas al operar dos lógicas principales: la del mercado y la del Estado. Según ABramo (2012b), existe una tercera lógica en este entramado de "ocupación popular del suelo urbano como forma dominante de acceso a la vivienda por parte de los pobres" (Pág. 38), entendida como la lógica de la necesidad.

De manera que, las distintas representaciones de informalidad, asociadas a la producción del espacio urbano, significan, en sí mismas, diferentes tipos de segregación al localizarse en determinados espacios urbanos apartados del contacto con otras clases socioeconómicas urbanas (VARGASDíAz \& al., 2010), lo que configura una compleja trama de factores en la aparición, permanencia e importancia de la construcción de la ciudad informal (FIG. 1).

\subsection{Algunas lógicas de la segregación socioespacial inmersas en la ciudad informal}

Llegados a este punto, vale la pena acotar una serie de lógicas señaladas por WACQUANT (2007) que, según sus palabras, alimentan la nueva marginalidad, reconfiguran los atributos de la pobreza urbana y, en conjunto, (re)establecen los rasgos de la segregación socioespacial en nuestras ciudades - a partir de procesos de territorialización-. Lo anterior, con el fin de considerarlas como potenciales advertencias epistemológicas aplicables a la ciudad informal y evidenciar su composición en tanto formas de segregación. 


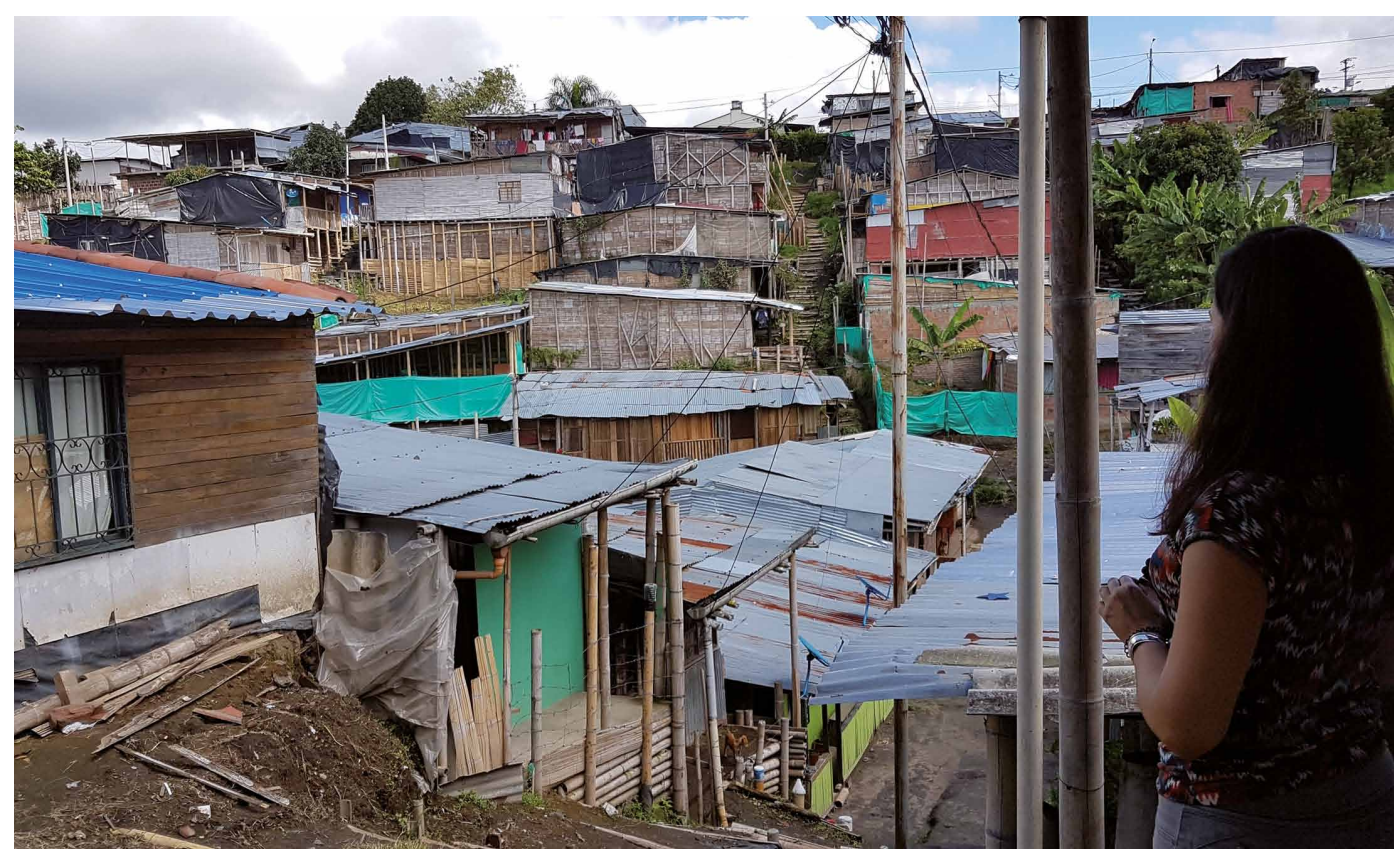

FIG. 1/ Panorámica del asentamiento humano Nuevo Armenia.

Fuente: Elaboración propia.

En primer lugar, Wacquant señala que la nueva marginalidad urbana no es producto de un posible atraso económico sino de la "desigualdad creciente en el contexto de un avance y una prosperidad económica global"; esta condición se evidencia en la ciudad de Armenia (contexto de estudio) en la diacronía de sus etapas de crecimiento ligadas a las primeras fases de (precaria) industrialización y a las continuas olas migratorias del campo a la ciudad. Situación que no ha sido marcada propiamente por sus avances dentro de la economía capitalista, sino por sus efectos negativos dado que allí se ha ampliado y profundizado el alcance de la marginalidad en una ciudad que, hace tres décadas, contaba con buenos índices sociales y económicos -dentro de los estándares nacionales-gracias a la pujante industria caficultora. Este modelo aureolar de la ciudad revela, a su vez, la sincronía de los fenómenos de diferenciación socioeconómica y espacial que provienen de la presión de las viejas tradiciones segregativas de la sociedad privilegiada local, conjugada con los especulativos mecanismos de la promoción inmobiliaria cuyas operaciones tienden a la creación o la mantención de la estructura espacial reservada a las élites.

En segundo lugar, el autor alude a la denominada "transformación de la esfera del trabajo" que se evidencia, para el caso de estudio, en la eliminación del empleo asalariado del sector rural de la región -y del país-, bien sea por los efectos de la economía cafetera o por las políticas relacionadas con lo rural que no hacen atractivo el trabajo en el sector agrícola. Lo anterior ha provocado que "una fracción significativa de la clase obrera se ha[ya] convertido en superflua" y generado una población trabajadora excedente para la economía local de Armenia, una ciudad continuamente "invadida por los éxodos de una larga guerra agraria" (APRILEGNISET, 1992: 167). Esta situación, presente en la capital del departamento del Quindío desde mediados el siglo XX, ha convertido a la ciudad en un escenario de confrontación social y de lucha de clases sobre el espacio urbano.

Al seguir la ruta planteada por Wacquant, en tercer lugar, se hace alusión a la "reconstrucción de los Estados de Bienestar" como grandes productores de desigualdad y marginalidad urbana al configurar en nuestras ciudades programas o políticas que, aunque destinados a amortiguar las consecuencias de la pobreza y sus impactos sociales y espaciales, también contribuyen a determinar las condiciones de aquellos que quedan relegados. En nuestro caso, este es el resultado, por un lado, de la inexistencia (o poca claridad) de políticas sobre el acceso al suelo urbano como consecuencia del 'achicamiento' de las estrategias que materialicen la función social de la propiedad privada y, por otro lado, la 'desarticulación' de las políticas nacionales en la aplicación de los subsidios 
para el acceso a la vivienda. Esto repercute en espacialidades que desconocen las realidades socioculturales de aquellos a quienes las referidas políticas pretenden cobijar; lo que en últimas se convierte en la privatización de políticas sociales. Situación que ha impedido que los habitantes de los espacios urbanos informales se constituyan en ciudadanos sujetos de derechos, relegándolos a la espera de alternativas de solución provenientes de agentes externos (CASTAÑeda-PÉReZ \& MeJía LoTERO, 2017; CASTAÑEDA-PÉREZ, 2018); un escenario propicio para la permanencia de los sistemas políticos tradicionales que ignoran las potencialidades y recursos de los grupos humanos.

Por último, el mencionado autor hace alusión a la concentración y estigmatización de las dinámicas espaciales en donde la nueva marginalidad urbana evidencia una tendencia a conglomerarse y acumularse en áreas específicas, claramente identificadas por las personas ajenas a ellas. Lo anterior, derivado del efecto del flujo direccional que marca la tendencia histórica de los espacios destinados a la clase dominante, lo que devela dinámicas segregativas residenciales y funcionales que, a su vez, obedecen a condiciones comparativas de localización y entorno. Esto, tradicionalmente en Armenia, corresponde con la ocupación irregular del suelo en laderas contiguas a quebradas cercanas, a su vez, al centro consolidado de la ciudad y, más recientemente, a sectores urbanos periféricos.

De ahí que la ciudad informal, generada tanto por procesos de desterritorialización —resultado ineludible de conflictos propiciados por la expansión de políticas que reducen la presencia del Estado en los diferentes campos económicos-, como por procesos de reterritorialización debido a múltiples factores como la pobreza y la falta de oportunidades; se convierta en territorios intersticiales ${ }^{4}$ producto de las políticas estatales en materia de vivienda, urbanismo y ordenamiento territorial. Es por esto que su surgimiento, consolidación y permanencia son, en esencia, una cuestión política que conlleva, inevitablemente, un trasfondo social. En palabras de TORRES (2009):

\begin{abstract}
"El hábitat autoproducido que alimenta la ciudad informal se ha convertido en una alternativa a la falta de repuestas de los gobiernos nacionales y locales frente a los déficits urbanos en materia de hábitat y vivienda (...) un estructurador de los territorios urbanos de la ciudad formal, mediante procesos de planeación no regulada pero que son admitidos. (Pág. 21)"
\end{abstract}

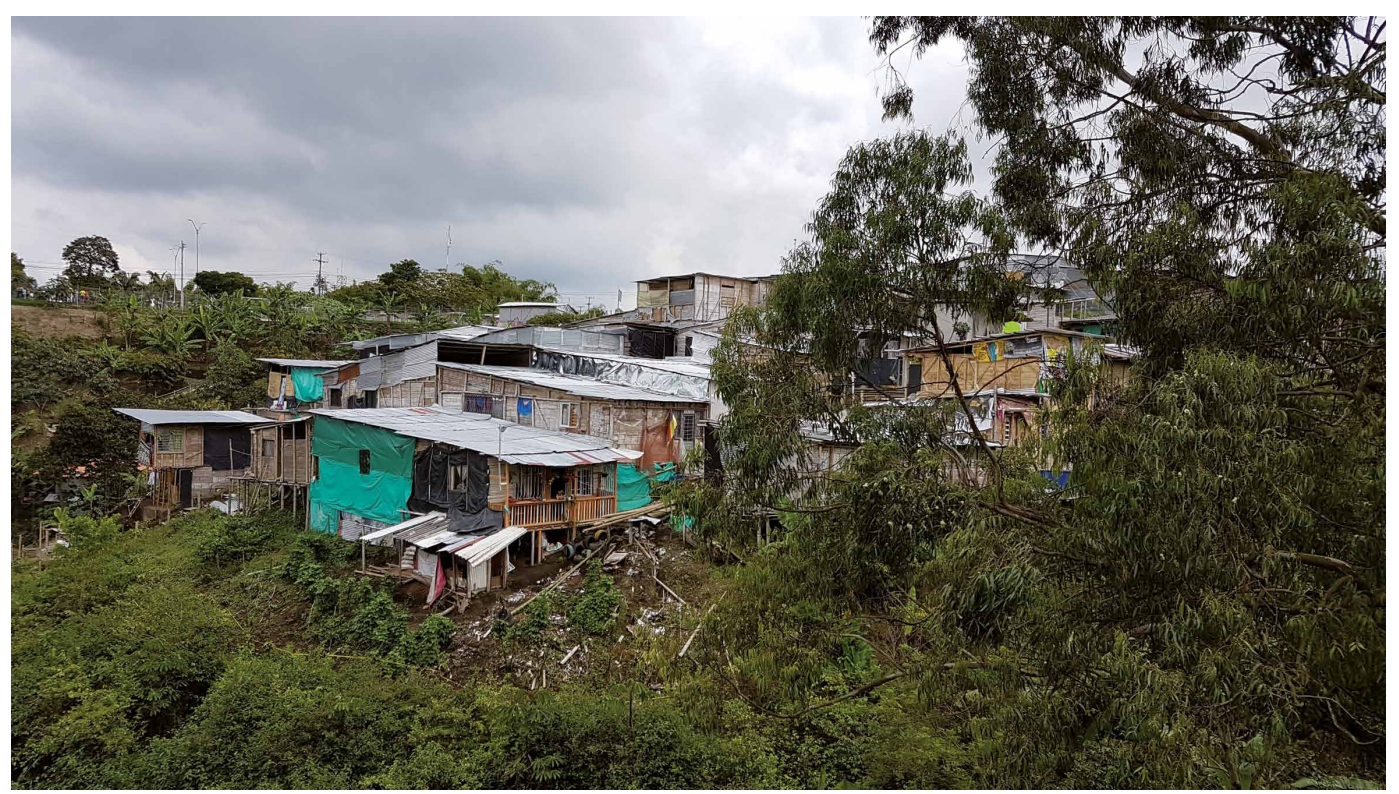

FIG. 2/ Vista del asentamiento El Tesoro desde el Asentamiento Nuevo Armenia.

Fuente: Elaboración propia.

${ }^{4}$ Considerados estos no solo como simples espacios físicos
remanentes de los diversos y discontinuos procesos planea-
ción centralizados, también como resultado de la amalgama de interacciones e irrupciones entre múltiples actores que coexisten en una situación o contexto espacial (intersticial) definido. 
En síntesis, este tipo de ciudad, al tratarse de una realidad socioespacial urbana, surge de la configuración de nuevos territorios que omiten los formalismos de la noción de propiedad al hacer uso de tierras incultas o baldías que, con el fin de subsanar una necesidad habitacional, crean redes de relaciones a partir de nuevas configuraciones espaciales enmarcadas en disputas por el territorio. Como resultado, son los habitantes quienes a partir de su posición de grupo o clase y su localización en la ciudad, se apropian del espacio urbano y lo significan (LICONA 2007) y, en consecuencia, construyen sobre este sentidos y modos de habitar.

De manera que, se puede entender la ciudad informal como un ejercicio de producción social del hábitat por parte de sujetos, actores y en ocasiones agentes (CAPEL SÁEZ, 2013) impulsados por necesidades que motivan acciones (emplazamiento, ocupación, implantación, habitación, dominio o apropiación) sobre el espacio en el acceso a bienes y servicios urbanos. A su vez, es posible encontrar, en dichas acciones, una

"conexión de eslabones semióticos, organizaciones de poder, circunstancias relacionadas con las luchas sociales" (Deleuze \& Guattari, 2004: 13),

las cuales necesariamente producen cambios en la espacialidad urbana y evidencian aquella esencia de la ciudad en tanto proceso, horizonte y práctica (FIG. 3).

\section{Desde una la realidad in situ}

Como ya se ha mencionado, los procesos de construcción de los espacios urbanos informales se presentan, generalmente, en zonas segregadas social y espacialmente, que son, a la larga, las que determinan las condiciones de vida de sus habitantes quienes, con frecuencia, son catalogados como invasores (CRAVINO \& VARELA, 2008). Ahora bien, conviene subrayar que dicho espacio de vida no solo se limita a la ubicación material donde se localizan los medios necesarios para el ejercicio del habitar y donde se desarrollan las relaciones sociales, sino que este

"se constituye en un sujeto mismo de producción. Así, el espacio adquiere una materialidad y una subjetividad propia que lo hacen histórico y dinámico" (JIMÉNEZ \& NovOA, 2014: 8),

lo que permite abordarlo como hecho territorial, como proceso y como producto a través de sus características propias.

A fin de comprender este fenómeno es necesario enfocarlo en marcos de desigualdad y exclusión, en los cuales, cada actor, ya sea público o privado, interviene en función de determinados intereses políticos, económicos y sociales, que favorecen u obstaculizan el proceso de formación y configuración territorial de nuestras ciudades. En esta ecuación, en la que por un lado encontramos sujetos vulnerables, errantes y sin tierra, y por otro lado nos topamos un espacio intersticial que puede encontrarse dentro de los límites territoriales o

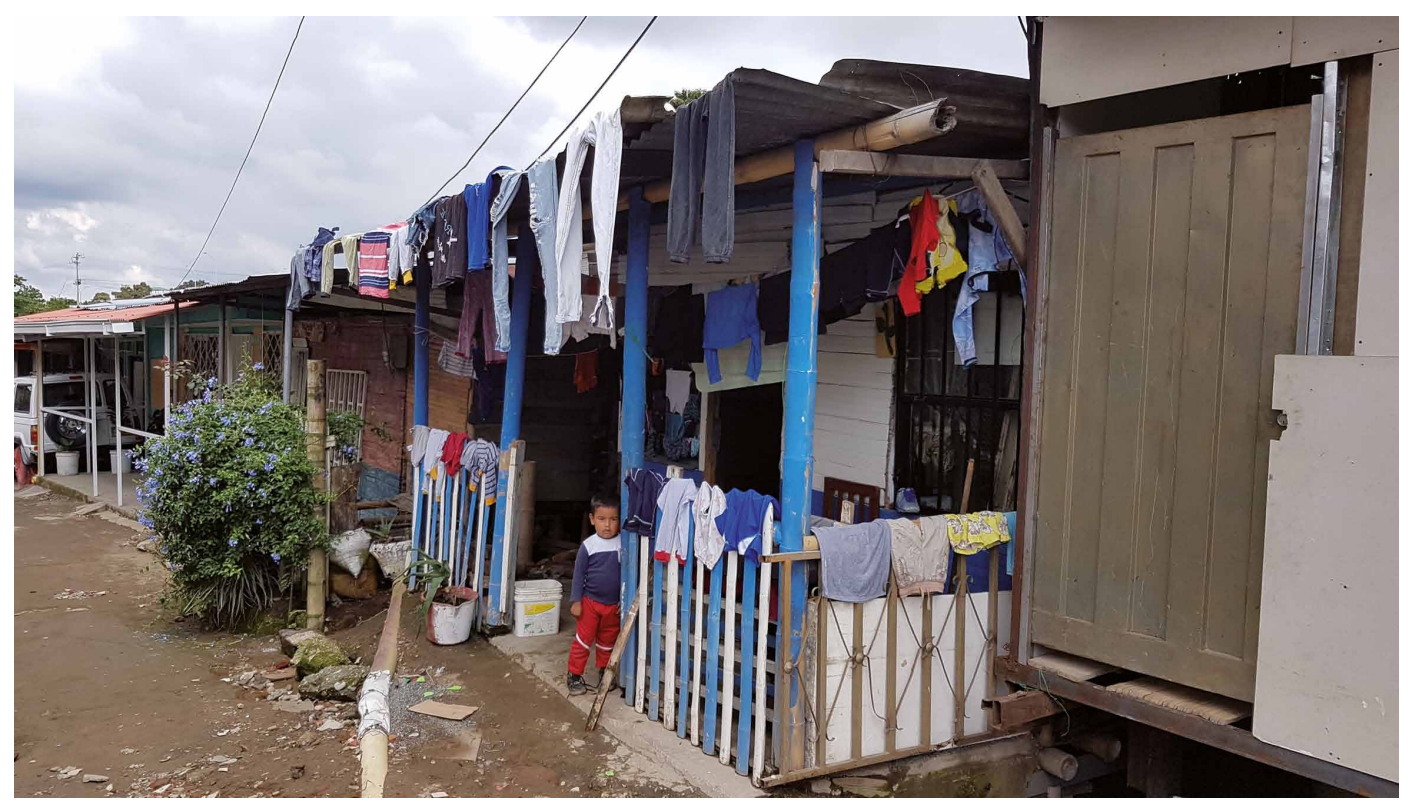

FIG. 3/ Vivienda del asentamiento Nuevo Armenia. 
puede pertenecer al poder jurídico y absoluto de un agente (bajo la idea de propiedad privada), se termina por definir el hecho territorial de la ciudad informal y todas las aristas que se derivan de él. En el caso de la ciudad de Armenia, a lo anterior se suman las necesidades habitacionales de la creciente y predominante población urbana, las actuales dificultades de empleo y los altos costos del suelo urbano disponible y de la vivienda comercialmente ofertada, constituyéndose en los principales factores del crecimiento informal de la ciudad. Una forma extendida de ocupación del territorio que reproduce la segregación socioespacial urbana.

Con el propósito de discutir acerca de un caso en concreto, en este punto, se hace referencia a un asentamiento humano informal de la ciudad donde se percibe la noción de territorialidad y de manejo territorial; es decir, donde existe afecto por el lugar y donde se han comenzado a establecer principios de organización entre los individuos que lo conforman. Es el resultado de un proceso de producción social del espacio que incorpora

"actos sociales, acciones de sujetos tanto colectivos como individuales que se despliegan sobre él, se expresan y encuentran en él prohibiciones" (LeFeBVRE, 2013);

es decir, múltiples entrecruzamientos en lugares determinados que reflejan, en buena proporción, la manera como históricamente nuestras ciudades se han configurado espacialmente.

Se trata del asentamiento informal de la ladera de la ciudadela Nuevo Armenia (etapas I y II) localizado en un terreno propiedad de la municipalidad de Armenia con destinación a uso público y que, en principio, hacía parte de las áreas de cesión obligatoria gratuita para el municipio ${ }^{5}$. Por esta razón, los procesos de ocupación y apropiación (promovidos inicialmente por los propios habitantes de la urbanización formal) han desencadenado en diversos conflictos, tanto frente al titular del predio, como con los vecinos del sector. Dichos procesos se originaron aproximadamente en el año 2002 sobre un terreno remanente del proyecto urbanístico Ciudadela Nuevo Armenia ${ }^{6}$.

Este asentamiento se caracteriza por tener largas y angostas calles, construidas entre el barro, las

\footnotetext{
${ }^{5}$ Artículo 20 POT 1999-2006 (Concejo Municipal de Armenia 1999) y Artículo 244 POT 2009-2023 (Concejo Municipal de Armenia 2009).

${ }^{6}$ Urbanización promovida durante el transcurso de la reconstrucción del eje cafetero post-terremoto de 1999, una alternativa de reubicación de familias en el marco de la conocida "vitrina inmobiliaria" del Fondo para la Reconstrucción y Desarrollo Social del Eje Cafetero (FOREC), un proceso catalogado como "novedoso" para la adjudicación de planes de vivienda en Armenia que consistió en una bolsa de oferta de
}

piedras, las llantas recicladas y la basura acumulada. Son calles que implican descensos y ascensos, con casas a sus costados, unas al lado de otras, construidas con madera, ladrillo, bahareque y lonas, entre otros materiales rudimentarios (FIG. 4). También es posible entrever allí, problemáticas en torno a la seguridad y el consumo de sustancias psicoactivas en las esquinas de las calles del barrio contiguo. Una de sus lideresas, al describir las condiciones bajo las cuales se formó el asentamiento, menciona que:

"este ha sido el resultado de olas migratorias de distintas zonas del país, e incluso de zonas internas del departamento, a razón del conflicto armado, del desempleo, de la pauperización de las zonas rurales y/o la falta de oportunidades, entre otras razones" (M. ZABALA, comunicación personal, 30 de abril de 2018).

Allí es posible visibilizar cultivos pequeños en la parte posterior de las viviendas que colindan con el arroyo La Cristalina y jardines con coloridas flores a lo largo de su callejón principal.

En el asentamiento, las dinámicas de producción, ocupación y apropiación del espacio son el resultado de un ejercicio de mercantilización irregular del suelo sobre el que se localiza el asentamiento. Se trata dela forma predominante de acceso a la tierra urbana (ABRAMO, 2012a) y una de las características de la formación socioespacial de las ciudades de la región como mecanismo de provisión de suelo y vivienda para sectores populares. Actualmente, las cerca de 45 familias que habitan este lugar se encuentran en proceso de creación de la figura de gestión comunitaria conocida como Junta de Acción Comunal (JAC) ${ }^{7}$, es decir, crear su propia organización social y adoptar un sistema de reglas de conducta y normas de convivencia con el fin de planificar y reglamentar el uso adecuado de su espacio vital.

Sin embargo, las condiciones de tenencia del suelo han generado múltiples inconvenientes para sus familias y líderes quienes han afrontado diversas acciones de desalojo por parte de autoridades civiles y policiales. Frente a ello, se han visto obligados a librar una disputa por la defensa de sus nuevas raíces, una lucha desigual por su condición de vulnerabilidad, ya sea por proyectos donde los damnificados seleccionaron su vivienda de una amplia gama de proyectos.

${ }^{7}$ La junta de acción comunal es una organización cívica, social y comunitaria de gestión social, sin ánimo de lucro, de naturaleza solidaria, con personería jurídica y patrimonio propio, integrada voluntariamente por los residentes de un lugar que aúnan esfuerzos y recursos para procurar un desarrollo integral, sostenible y sustentable con fundamento en el ejercicio de la democracia participativa (CONGRESO DE LA República de Colombia 2002). 


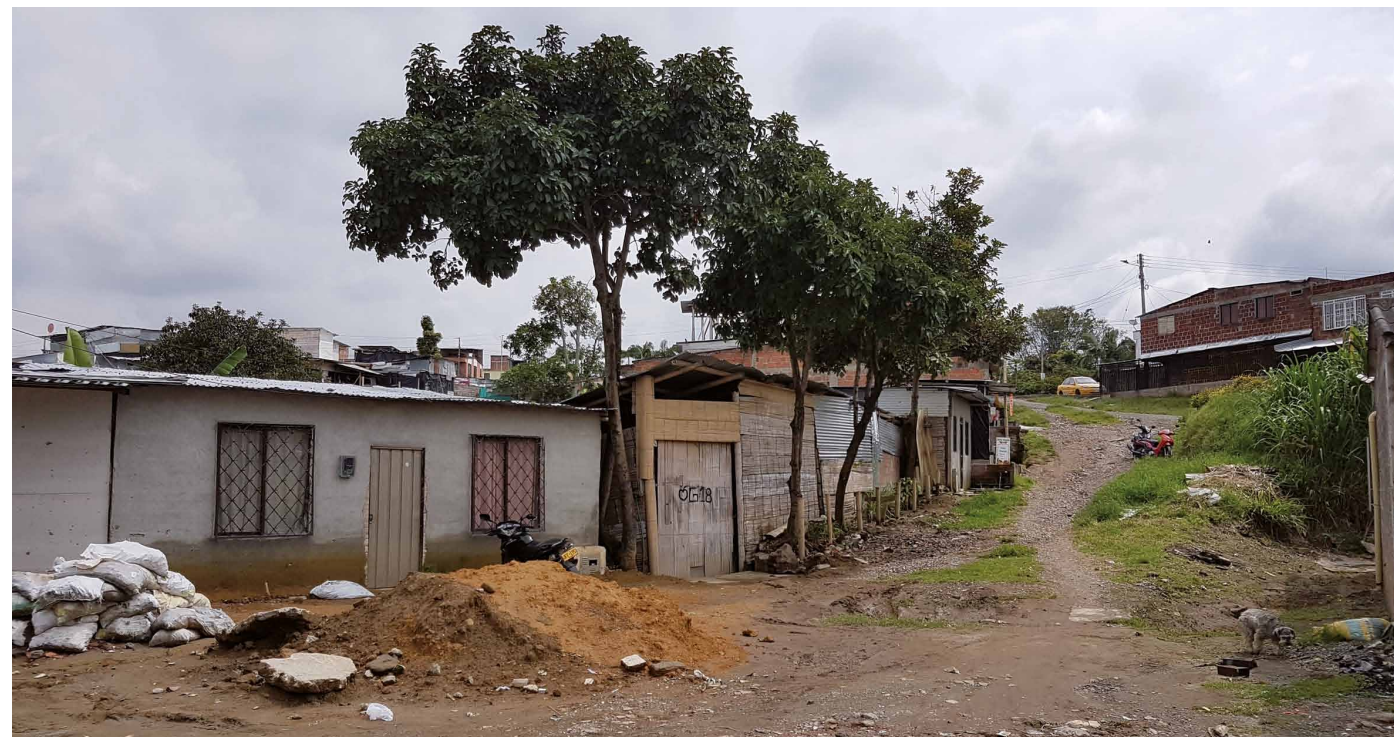

FIG. 4/ Calle del asentamiento Nuevo Armenia.

Fuente: Elaboración propia.

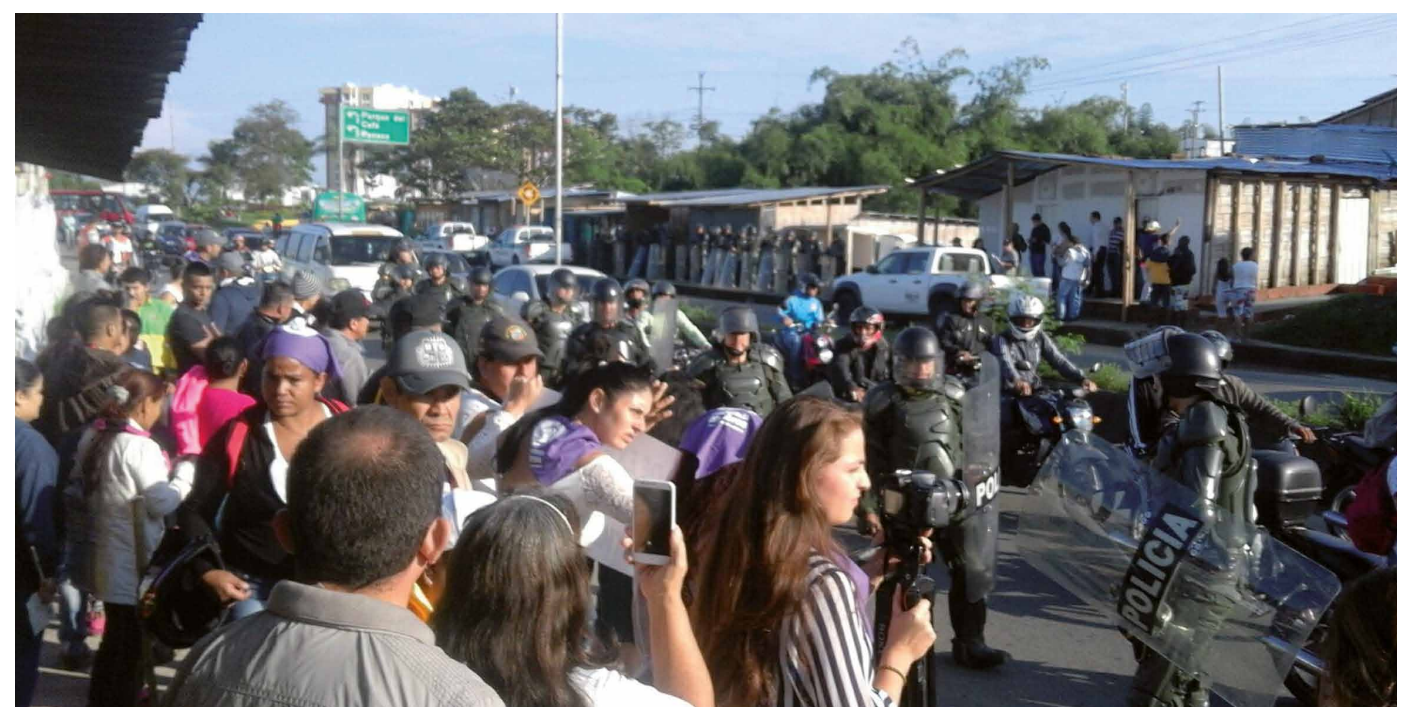

FIG. 5/ Intento de desalojo de habitantes del asentamiento.

la inseguridad infraestructural de sus viviendas, o por la incertidumbre de tenencia del suelo sobre el cual se localizan (FIG. 5). Son luchas que se han llevado a instancias legales, para lo cual han realizado distintos procesos organizativos y de pronunciamiento público que conllevan a la exigencia de derechos y de la intervención estatal para la mejora de las condiciones de vida de las familias que allí habitan. Este 'hacer frente' los ha marcado, porque han sufrido el temor de ser desalojados y de ser, nuevamente, desterritorializados.
Justo aquí se puede advertir una relación entre estos procesos de urbanización y pobreza, donde muchos de los pobladores que migran a las urbes terminan en peores niveles de vida ya que no pueden acceder a las ventajas que, suponen, les brindaría la ciudad (LeFEBVRE, 1968). Todo ello, en gran parte, porque la presencia del Estado es deficiente y el proceso de reconocimiento legal de estos territorios implica que allí se deben ofrecer todos los beneficios de una ciudad formal. En resumen, este tipo de territorializaciones son, para 
sus habitantes, formas de materializar el derecho al territorio, la vida y la ciudad.

Por otro lado, la disputa por la vivienda (que es entre otras por el territorio y el habitar) también les ha generado conflictos con la municipalidad frente a la naturaleza de la propiedad. Estas disputas oscilan entre la condición de la ilegalidad (como lo comprende el discurso institucional) y la apropiación del territorio. Más aún, cuando entre sus pobladores no ha sido fácil la configuración de una forma asociativa que permita la gestión acertada de sus procesos de territorialización, en tanto manifestación del 'estamos aquí' y 'tenemos derecho habitar'.

En definitiva, el espacio urbano informal presentado denota una serie de gestas que lo configuran como producto, como medio de acción -y de apropiación/dominio- desde lo social (individual o colectivo) sobre lo físico. Actos que otorgan derecho y valor de uso a espacios por medio de acciones de emplazamiento (dinámicas y procesos), de ordenación del suelo (poner en lugar, hacer un lugar) y de habitación; todo ello en busca de la preservación y ampliación del espacio vital con el fin de satisfacer la necesidad de habitar, permanecer y residir. Algo que, como se ha expuesto, no está exento de conflictos.

Estos son los ciudadanos que, al construir y defender su espacio de residencia, no sólo edifican una vasta ciudad nueva, sino que también, sobre esa misma base, proponen un orden de ciudadanía diferente y reflejan en su hábitat los códigos de la sociedad en la cual se inscriben como individuos. Por ello, han actuado con una lógica propia y fuerte: la de la ciudad informal; una lógica territorial que debe ser comprendida si se pretende proponer alternativas efectivas.

\section{Conclusiones}

El proceso de crecimiento urbano, conocido con el término de "urbanización", no solo se vincula en nuestros países al curso de producción de ciudad realizado dentro de las normas legales y urbanas vigentes; este puede también ser utilizado para referirnos a la acción de los propios habitantes de la denominada ciudad informal ya que en ella también se realiza un ejercicio de consolidación y/o expansión de suelo urbano (CRAVINO, 2006). Proceso que, a su vez, dinamiza un conjunto de acciones individuales y colectivas que promueven

\footnotetext{
${ }^{8}$ Conformado por la unión de la palabra y el contenido de urbano y rural para procurar comprender y explicar, en este
}

la producción de ciudad y la consolidación de asentamientos informales. Por tanto, una de las características físico espaciales predominante de las ciudades latinoamericanas se constituye a partir de la superposición de dos formas de producción del espacio urbano: la formal y la informal.

Por su parte, en las ciudades colombianas, en general, se ha dado una ocupación del suelo (urbano y rural) sin planificación en el mediano y largo plazo, se ha privilegiado la actuación individual y la localización de actividades comerciales, de servicios e industria por encima de la actividad residencial. Dichas acciones presionan el crecimiento de nuestras ciudades por medio del desplazamiento de población hacia zonas inadecuadas o de vocación agrícola donde se hacen necesarias altas inversiones en infraestructura urbana y equipamientos. Esta dinámica urbana ha sido costosa desde el punto de vista financiero, social, ambiental y urbano, y también en lo productivo (desde lo rural) al romper el "acontecer complementario" (SANTOS, 2005) de las relaciones de producción e intercambio entre ciudad y campo.

Dicho brevemente, la ciudad informal es una configuración socioespacial producto de la interacción entre fuerzas macroestructurales, políticas estatales y el esfuerzo de algunos grupos humanos por auto satisfacer la necesidad básica de habitar (FIG. 6). Esta se deriva de los actuales problemas para el acceso a la vivienda y al suelo urbano, en tanto proceso alternativo a los impuestos por el modelo de desarrollo dominante. Es, al mismo tiempo, resultado de la dependencia al modelo capitalista y de múltiples maneras de exclusión y marginación de poblaciones a ejercer su derecho al territorio.

El resultado: "islas de precariedad" (JANOSCHKA, 2006:89) presentes en la ciudad de Armenia, donde se percibe, por un lado, una histórica ocupación informal de suelo no apto al interior de la ciudad en áreas definidas por el POT como zonas de riesgo o de protección ambiental; $y$, por otro lado, una reciente ocupación discontinua del suelo rururbano ${ }^{8}$ que conlleva la extensión de las dinámicas económicas, productivas y culturales del centro de la ciudad. Estos procesos de consolidación y extensión modifican el territorio en cuanto su comprensión y organización al producir una estructura "Com-fusa" (AвRAmo, 2012b) de territorialidad. Es por esto que, en su problematización y manejo es necesario hacer confluir una perspectiva relacional a la forma como se concibe la segregación socioespacial urbana, de manera que se pueda construir una nueva mirada sobre la desigualdad

caso, la constitución y los procesos ocurridos en las áreas de expansión de las ciudades (CARDOSO AND FRITSCHY, 2012) 


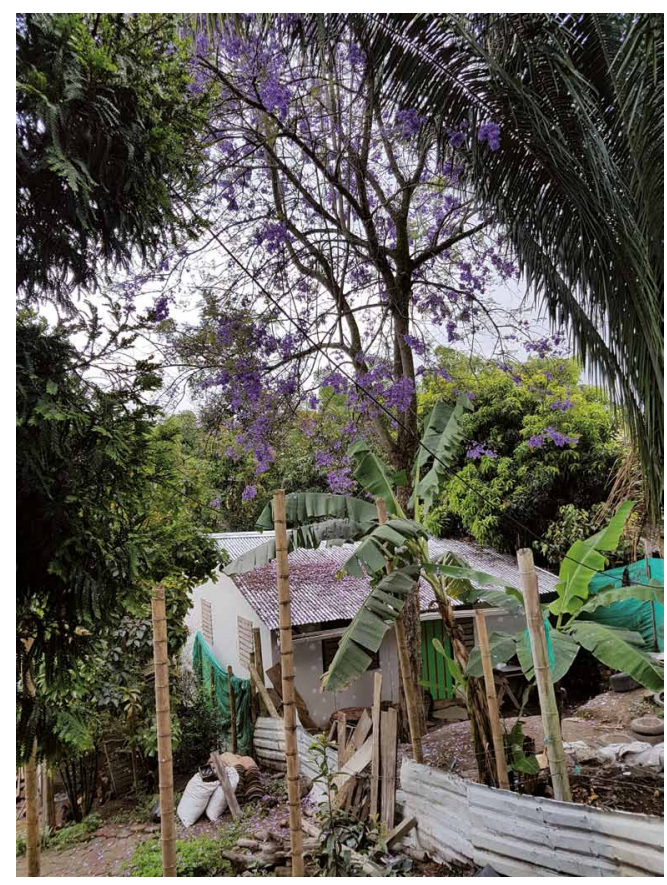

G. 6/ Vivienda del asentamiento Nuevo Armenia.

Fuente: Elaboración propia.

y la relegación, que supere, a su vez, el individualismo metodológico alentado por el positivismo y se convierta en el objetivo empírico principal de nuestras políticas públicas y los discursos oficiales sobre la materia.

En consecuencia, el estudio de las transformaciones espaciales no solo advierte una relectura del hacer ciudad, también requiere tener en el horizonte de análisis los conflictos y las dinámicas de conflictividad que definen este producto social en su conjunto. En tal sentido, se invita a (re)leer la ciudad informal

\begin{abstract}
"como obra, como valor de uso, como goce, como disfrute, como belleza y como creación colectiva de sus ciudadanos, sobre la que ellos deciden y en la que ellos intervienen" (LefEBVRE, 2013: 23).
\end{abstract}

A partir de allí, se les otorga a estas territorialidades un carácter de actividad creativa libre, una expresión de la potencialidad humana de apropiarse del espacio y convertirlo en lugar, adaptarlo, usarlo, transformarlo y verter sobre este la afectividad del usuario.

Se convierte en una invitación a debatir teóricamente dichas acciones y a reconocer que estos territorios constituyen y encarnan una territorialidad alternativa al modelo de desarrollo hegemónico, desde donde suelen diseñarse y ejecutarse las estrategias y políticas que han demostrado su desacierto en el abordaje de este hecho territorial. En consecuencia, se trata de pensar en la acción de ocupar desde la perspectiva del habitar, lo que significa concebir la apropiación de estos territorios a partir de su vivencia, de su adaptación, uso, transformación y carga de sensibilidad e imaginación por parte de quienes lo habitan y convierten en lugares.

\section{Bibliografía}

Abramo, P. (2003): “La Teoría Económica de La Favela: Cuatro Notas Sobre La Localización Residencial de Los Pobres y El Mercado." Ciudad y Territorio: Estudios Territoriales XXXV (136- 137): 1- 24.

- (2010): "Mercado Informal de Alquiler: Nueva Puerta de Acceso a Los Asentamientos Populares." En Arrendamiento y Vivienda Popular en Colombia Como Alternativa Habitacional, editado por Clemencia Escallón Gartner, 53- 78. Bogotá D.C.: Universidad de Los Andes.

- (2012a): "Ciudad informal Com-Fusa: El Mercado y La Producción de La Territorialidad Urbana Popular." En Irregular. Suelo y Mercado En América Latina, editado por Clara Eugenia Salazar, 85. México D.F.: El Colegio de México.

- (2012b): "La Ciudad Com-Fusa: Mercado y Producción de La Estructura Urbana En Las Grandes Metrópolis Latinoamericanas." EURE 38 (114): 35-69. https://doi.org/10.4067/S0250$\underline{71612012000200002}$

ApRILe-Gniset, J. (1992): La Ciudad Colombiana. Siglo XIX y Siglo XX. Bogotá D.C.: Banco Popular, Fondo de Promoción de la Cultura.

Aubán Borrell, M. (2017): "La Dignidad de Los Márgenes. Aproximaciones Afectivas a La Ciudad Informal." INVI 32 (91): 67-89.

Capel SÁez, H. (2013): "Actores, Agentes y Reglas de Juego." En La Morfología de Las Ciudades. III. Agentes Urbanos y Mercado Inmobiliario, 18-51. Barcelona: Del Serbal.

Cardoso, M. M., \& Fritschy B. A. (2012): "Revisión de La Definición Del Espacio Rururbano y Sus Criterios de Delimitación." Contribuciones Científicas GAEA, no. 24: 27-39

Castañeda-Pérez, Y. (2018): "Ciudades de Barro: Asentamiento Informal Fundadores Bajo de Armenia, Colombia." AUS, no. 23: 49-55. https://doi.org/10.4206/aus.2018.n23-08

- (2019): "Ciudades de Barro: Acacias Bajo, Un Asentamiento Informal en Armenia, Colombia." Ciudad y Territorio: Estudios Territoriales LI (201): 189-96.

- \& Mejia Lotero F. M. (2017): Construir Para Transformar. Alternativas Para El Desarrollo Autogestionado y Sustentable En El Asentamiento Informal El Milagro de Dios Del Municipio de Armenia. Armenia, Colombia: Universidad La Gran Colombia seccional Armenia.

ClicheVsKY, N. (2000): "Informalidad y Segregación Urbana En América Latina. Una Aproximación.” Medio Ambiente y Desarrollo. Vol. 28. Santiago de Chile. 
Concejo Municipal de Armenia (1999): "Acuerdo Municipal Nº01 de 1999 Por Medio Del Cual Se Aprueba El Plan de Ordenamiento Territorial Del Municipio de Armenia, Para El Periodo 1999-2006." Gaceta Municipal de Armenia, no. s.n.

- (2009): "Acuerdo Municipal N 019 de 2009 Por Medio Del Cual Se Aprueba El Plan de Ordenamiento Territorial Del Municipio de Armenia, Para El Periodo 2009-2023." Gaceta Municipal de Armenia, $\mathrm{n}^{\circ} .1185$

Congreso de la República de Colombia. (1997): "Ley 388." Diario Oficial, no. 43127.

- (2002): "Ley 743 Por La Cual Se Desarrolla El Artículo 38 Constitución Política de Colombia En Lo Referente a Los Organismos de Acción Comunal." Diario Oficial, no. 44826. https://www.funcionpublica.gov.co/eva/gestornormativo/norma.php?i=5301.

Cravino, M. C. (2006): Las Villas de La Ciudad: Mercado e Informalidad Urbana. Buenos Aires: Universidad Nacional de General Sarmiento.

Cravino, M. C., \& Varela, O. D. (2008): "Mil Nombres Para Mil Barrios. Los Asentamientos y Villas Como Categorías de Análisis y de Intervención." En Los Mil Barrios (in)Formales. Aportes Para La Construcción de Un Observatorio Del Hábitat Popular Del Área Metropolitana de Buenos Aires, Editado por María Cristina Cravino, 45-64. Buenos Aires: Universidad Nacional de General Sarmiento.

Dumau, E. (2003): "La Ciudad Informal. El Orden Urbano y El Derecho a La Ciudad", editado por X Encontro Nacional da Associação Nacional de Pós-Graduação e Pesquisa em Planejamento Urbano e Regional, 11. Belo Horizonte: ANPUR.

Deleuze, G., \& Guattari, F. (2004): Mil Mesetas. Capitalismo y Esquizofrenia. 6a. Valencia, España: Pre-textos.

FernÁndez Wagner, R. (2008): “Los Asentamientos Informales Como Cuestión. Revisión de Algunos Debates." En Los Mil Barrios (in)Formales. Aportes Para La Construcción de Un Observatorio Del Hábitat Popular Del Área Metropolitana de Buenos Aires, editado por María Cristina Cravino, 15:1344. Buenos Aires: Universidad Nacional de General Sarmiento. https://doi.org/10.24220/2318-0919v15n3a4207

FrASER, N. (2008): Escalas de La Justicia. Traducido por Antoni Martínez Riu. Barcelona: Herder Editorial.

Harvey, D. (2012): Ciudades Rebeldes: Del Derecho de La Ciudad a La Revolución Urbana. Madrid: Akal.

JanosCHKA, M. (2005): "De Ciudades Dispersas a Ciudades Perforadas. Una Nueva Fase de Transición Demográfica." En Gobernanza, Competitividad y Redes: La Gestión En Las Ciudades Del Siglo XXI, editado por Carlos De Mattos, 151-72. Santiago de Chile: Instituto de Estudios Urbanos y Territoriales, Pontificia Universidad
Católica de Chile.

- (2006): "El Modelo de Ciudad Latinoamericana Privatización y Fragmentación Del Espacio Urbano de Buenos Aires: El Caso Nordelta." In Buenos Aires a La Deriva. Transformaciones Urbanas Recientes, edited by Max Weich Guerra, 80- 117. Buenos Aires: Editorial Biblos.

Jiménez, C. \& NovoA, E. (2014): Producción Social Del Espacio. El Capital y Las Luchas Sociales En La Disputa Territorial. Bogotá D.C.: Ediciones desde abajo.

Lefebvre, H. (1968): El Derecho a La Ciudad. Paris: Ediciones Anthropos.

- (2013): La Producción Del Espacio. Editado por Juan Marqués. Madrid: Capitán Swing.

LiconA, E. (2007): Habitar y Significar La Ciudad. Mexico D.F.: Universidad Autónoma Metropolitana.

Nates-Cruz, B. (2018): "El Derecho Al Territorio Como Base de La Justicia Cognitiva." Disparidades. Revista de Antropología, no. En prensa.

Pino Vásquez, A., \& OJeda Ledesma, L. (2013): "Ciudad y Hábitat Informal: Las Tomas de Terreno y La Autoconstrucción En Las Quebradas de Valparaíso." INVI 28 (78): 109-40. https://doi.org/10.4067/S0718-83582013000200004

Onu-Hábitat (2012): Estado de Las Ciudades de América Latina y El Caribe. Rumbo a Una Nueva Transición Urbana. Nairobi: Programa de las Naciones Unidas para los Asentamientos Humanos.

Puente Burgos, C. A. (2003): "Urbanización Clandestina: La Discusión Teórica." Bogotá D.C. http://www.javeriana.edu.co/cendex/pdf/DT 005-03.pdf

Raffestin, C. (2011): Por Una Geografía Del Poder. Traducido por Yanga Villagómez Velázquez. Michoacan: El Colegio de Michoacan.

Roncayolo, M. (1990): La Ville et Ses Territoires. Paris: Gallimard.

SABATINI, F. (2006): La Segregación Social Del Espacio En Las Ciudades de América Latina. Washington DC: Banco Interamericano de Desarrollo.

SANTOS, M. (2005): "El Retorno Del Territorio." OSAL: Observatorio Social de América Latina 6 (16): 251-61.

SoJA, E. W. (2014): En Busca de La Justicia Espacial. Traducido por Carmen Azcárraga. Valencia, España: Tirant humanidades.

TARDIN, R. (2006): "La Ciudad Informal." En Las Otras Geografías, editado por Joan Nogué i Font y Joan Romero, 389-404. Valencia: Tirant Lo Blanch.

Torres Tovar, C. A. (2009): Ciudad informal Colombiana: Barrios Construidos Por La Gente. Bogotá D.C.: Universidad Nacional de Colombia, Sede Bogotá, Facultad de Artes.

VARgas-Diaz, I. C. \& al. (2010): "Propuestas de Procesos de Mejoramiento Barrial Participativo En Asentamientos Informales." INVI 25 (69): 59-96.

WacQuAnt, L. (2007): Parias Urbanos. Marginalidad En La Ciudad a Comienzos Del Milenio. Traducido por Horacio Pons. Buenos Aires: Manantial. 